\title{
Non-fatal suicidal behaviour in rural Ethiopia: a cross-sectional facility- and population-based study
}

\author{
Abebaw Fekadu ${ }^{1,2^{*}}$, Girmay Medhin ${ }^{3}$, Medhin Selamu', Tsion Shiferaw ${ }^{1}$, Maji Hailemariam¹, Sujit D Rathod ${ }^{4}$, \\ Mark Jordans ${ }^{5}$, Solomon Teferra ${ }^{1}$, Crick Lund ${ }^{6}$, Erica Breuer ${ }^{6}$, Martin Prince $^{7}$, Tedla W. Giorgis $^{8}$, Atalay Alem ${ }^{1}$ \\ and Charlotte Hanlon ${ }^{1,7}$
}

\begin{abstract}
Background: Injury related to self-harm is one of the leading causes of global disease burden. As a formative work for a programme to implement comprehensive mental healthcare in a rural district in Ethiopia, we determined the 12-month prevalence of non-fatal suicidal behaviour as well as factors associated with this behaviour to understand the potential burden of the behaviour in the district.

Method: Population-based ( $n=1485)$ and facility-based $(n=1014)$ cross-sectional surveys of adults, using standardised, interview-based measures for suicidality (items on suicide from the Composite International Diagnostic Interview), depressive symptoms (the Patient Health Questionnaire) and alcohol use disorders (Alcohol Use Disorder Investigation Test; AUDIT)

Results: The overall 12-month prevalence of non-fatal suicidal behaviour, consisting of suicidal ideation, plan and attempt, was $7.9 \%$ (95\% Confidence Interval $(\mathrm{Cl})=6.8 \%$ to $8.9 \%$ ). The prevalence was significantly higher in the facility sample (10.3\%) compared with the community sample (6.3\%). The 12-month prevalence of suicide attempt was $4.4 \%(95 \% \mathrm{Cl}=3.6 \%$ to $5.3 \%)$, non-significantly higher among the facility sample $(5.4 \%)$ compared with the community sample (3.8\%). Over half of those with suicidal ideation (56.4\%) transitioned from suicidal ideation to suicide attempt. Younger age, harmful use of alcohol and higher depression scores were associated significantly with increased non-fatal suicidal behaviours. The only factor associated with transition from suicidal ideation to suicide attempt was high depression score. Only $10.5 \%$ of the sample with suicidal ideation had received any treatment for their suicidal behaviour: $10.8 \%$ of the community sample and $10.2 \%$ of the facility sample. Although help seeking increased with progression from ideation to attempt, there was no statistically significant difference between the groups.

Conclusion: Non-fatal suicidal behaviour is an important public health problem in this rural district. A more in-depth understanding of the context of the occurrence of the behaviour, improving access to care and targeting depression and alcohol use disorder are important next steps. The role of other psychosocial factors should also be explored to assist the provision of holistic care.
\end{abstract}

Keywords: Suicide attempt, Suicidal ideation, Suicidal plan, Suicidal behaviour, Low and middle income country, Ethiopia

\footnotetext{
* Correspondence: abe.wassie@kcl.ac.uk

${ }^{1}$ Department of Psychiatry, School of Medicine, College of Health Sciences,

Addis Ababa University, Addis Ababa, Ethiopia

${ }^{2}$ Department of Psychological Medicine, Institute of Psychiatry, Psychology

and Neuroscience, Centre for Affective Disorders, King's College London,

London, UK

Full list of author information is available at the end of the article
} 


\section{Background}

Injury related to "self-harm" is one of the leading causes of global disease burden in many parts of the world [1]. The burden is particularly high in high-income AsiaPacific countries and Eastern Europe, where the burden of disease caused by self-harm is ranked fifth and sixth, respectively [1]. Self-harm related disease burden is reported to be relatively lower in Western Africa (ranked 69th) and Eastern sub-Saharan Africa (ranked 32nd). However, given the overall scarcity of data and stigma surrounding self-harming behaviours, this apparently lower burden in Eastern sub-Saharan Africa may be due to under-reporting or the dearth of studies reporting on the subject. For example, in a large scale international study coordinated by the World Health Organization involving 11 "developing" and 10 "developed" countries, the 12 month prevalence of suicidal ideation, plans and attempts were slightly higher among participants from developing countries [2]. In fact, $85 \%$ of the over 800,000 annual suicide deaths [3] are likely to occur in low and middle income countries (LMICs), where resources to prevent suicide deaths are severely limited. Suicide might indeed be a hidden cause of death in traditional societies because of the high level of stigma and associated religious and cultural condemnation $[4,5]$. For example, in a study of 100 key informants, primarily consisting of community and religious leaders from Ethiopia [4], people who commit suicide were considered "condemned sinners" who do not deserve appropriate funeral rituals but should be buried in isolated unmarked place. Those who attempt suicide were "feared" and considered "cruel" and "untrustworthy".

Yet data from LMICs remain sparse and, where available, the incidence of suicide and non-fatal suicidal behaviour shows marked variability [6]. The potential role of rural residence on rate of suicidal behaviour is also not adequately explored. An old study evaluating the rate of suicide in West Africa [7] reported a higher rate of suicide among rural residents; however, the risk of under-reporting in this study is very high.

In studies from Ethiopia, the reported lifetime prevalence of suicide attempts varied between 0.9 and $14.8 \%$ $[8,9]$. The rate of suicide attempts was particularly high among the homeless in Addis Ababa [10] and those with mental disorders [11-13]. Studies from other African countries report a similarly variable prevalence of suicidal behaviour. In a study conducted in a primary care facility in Kenya, $12.7 \%$ of participants were reported to be at risk of suicide, although the specific rates for suicide attempt or ideation were not provided [14]. In Morocco, the one month prevalence of suicidal ideation was $6.3 \%$ [15]. A study from Nigeria reported a $3.2 \%$ prevalence of suicidal ideation and $0.7 \%$ for suicide attempt. [16] In South Africa, the lifetime prevalence of suicide ideation, plans and attempts were 9.1, 3.8 and $2.9 \%$ respectively [17]. Despite the relatively large variation, these figures indicate that suicidal behaviour is an important problem in Africa. Several risk factors for suicidal behaviour have been reported at the health system, community and individual level. The system level risk factors focus on access to means of suicide and health care. The individual factors include demographic features (female gender, younger age, lower education level, unmarried status) while stigma and discrimination are reported to be relevant community factors [3]. Mental disorders are perhaps the most important risk factors. Mood disorders, such as depression and bipolar disorder, impulse control disorder, and substance abuse are the most important disorders [18]. Given the dearth of data, particularly among rural communities, and the inconsistencies in prevalence figures, further studies to establish the prevalence and potential risk factors of non-fatal suicidal behaviour, such as demographic factors, depressive symptoms and alcohol use disorder [18], are required.

Moreover, non-fatal suicidal behaviours share risk factors with completed suicide [6] and are strong predictors of suicide even many years after the attempt [19]. It is therefore essential to understand non-fatal suicidal behaviour in order to develop intervention strategies which would also contribute to the prevention of suicide. In this study, we determined the prevalence of non-fatal suicidal behaviour (i.e. suicidal ideation, suicidal plan and suicide attempt). As in other studies [20], we defined suicidal ideation as the engagement in thoughts about self-inflicted harm to end one's life. Suicidal plan was defined as "the formulation of a specific method through which one intends to die". Suicide attempt represented "engagement in potentially self-injurious behaviour in which there is at least some intent to die."

The study was conducted as part of the formative phase of the Programme for Improving Mental Healthcare (PRIME) [21], a multi-country research programme consortium, which works with Ministries, local governments and communities to integrate mental health services in primary healthcare.

\section{Methods}

The data reported here were collected from a crosssectional population-based survey and a facility-based survey of adults aged 18 years and above.

\section{Setting}

The study was conducted in the Sodo district, Gurage Zone, Southern Nations, Nationalities and Peoples Region (SNNPR); a predominantly rural district located about $100 \mathrm{~km}$ south of the capital city, Addis Ababa. The population of the district is 161,952 persons $(79,356$ men; 82,596 women) living in 58 sub-districts (kebeles) 
[22]. The largest ethnic group in the district is Sodo Gurage (85.3 \%) followed by Oromo (11.6 \%) and Amhara (1.5\%) and Amharic is the official language. The majority of the population are Orthodox Christian ( 97.0 \%) with Muslims making up $\sim 2.3 \%$. Within Sodo district, primary care services comprise eight public health centres, staffed by nurses and health officers, and 58 health posts (community-based facilities) staffed by health extension workers, female high school graduates originally from the subdistrict and with one year of training in healthcare. Two health extension workers staff each health post. The nearest hospital is located in Butajira town, $30 \mathrm{~km}$ South of Buei town, the capital of the district. While this study was being conducted, no formal mental health care was being provided within the district although at present an integrated mental healthcare programme has started with the support of the PRIME project. The Sodo district was selected for PRIME because it is a relatively typical rural district for Ethiopia, and is located close to the research infra-structure of the Butajira research project on severe mental disorders and the Butajira Demographic Surveillance Site [23, 24]. The site is also within reasonable travel distance of specialist mental health services.

\section{Participants}

Participants were consenting adults, aged 18 years and above, who had been residing in the district for at least six months. For the population-based study, participants were selected through simple random sampling of households from the total list of the district households followed by random sampling of one adult from each selected household. A total of 1485 participants were included in the study. This sample size was calculated to estimate changes in treatment coverage for common mental disorders (CMD) as a result of interventions of PRIME. The prevalence of CMD was assumed to be about $10 \%$, which is a conservative approximation of the prevalence of CMD in Ethiopian studies [25]. For the facility-based study, participants were selected by allocating numbers of participants for each health centre proportional to the number of attendees registered over a two week period. Following that, actual participants were recruited consecutively from the outpatient clinic over a period of one to two weeks until the target sample size was reached. The facility sample was part of a baseline study looking at the detection of depression and alcohol use disorder by primary care staff and was powered for this purpose [26]. No separate sample size calculation was undertaken for this study on suicidality. Both the community and facility samples come from the same geographical catchment areas and both surveys were conducted within the same six month period in 2014.

\section{Assessment of non-fatal suicidal behaviour and potential risk factors}

The three categories of non-fatal suicidal behavior were suicidal ideation, suicidal plan and suicide attempt. The World Mental Health (WMH) Survey Initiative version of the World Health Organization (WHO) Composite International Diagnostic Interview (CIDI) [27] was adapted for assessing the 12 month prevalence of suicidal behaviour. A hierarchy of single item questions explored these behaviours: Suicidal ideation: "Have you thought of taking your life in the past 12 months?"; Suicide plan (asked of those who had suicidal ideation): "Did you ever make a plan for taking your own life at any time in the past 12 months?"; Suicide attempt (asked to those who answered they had ideation or a plan): "Have you attempted to take your own life in the past 12 months?" The help seeking items in the CIDI were also adapted to evaluate help seeking behaviour in the sample. The adaptation was primarily to include services relevant for the setting.

The CIDI was used previously in Ethiopia in various population-based studies [12, 13, 28] and had established reliability and acceptability [29].

The AUDIT [30] was developed by the World Health Organization (WHO) as a screening tool to indicate problematic consumption of alcohol in the previous 12 months in people attending primary care facilities [31]. The AUDIT has ten items, each rated on a four-point scale, giving a total score ranging from 0 to 40 . Although not validated in the Ethiopian setting, the AUDIT has been used in neighbouring countries [32, 33]. Local alcoholic beverages were converted into standard equivalent alcohol units [34]. AUDIT score of 16 or more, corresponding with at least hazardous alcohol use, was considered a potential risk factor for suicidality.

Depressive symptoms were assessed using the 9-item patient health questionnaire (PHQ-9), a 9-item questionnaire developed to assess probable depression in the primary care setting [35]. The PHQ-9 could be used either as a continuous scale or the scores may be categorised into severity grades, typically as mild (score of 5-9), moderate (score of 10-14), moderately severe (score of 15-19) and severe (score of 20 and above). This latter categorisation can potentially assist clinical decision making, and we have used categories to establish severity of depression in modelling risk factors. The PHQ-9 has been validated in the general hospital setting in Ethiopia [36] as well as primary care settings in preparation for the current study [37].

Other potential risk factors included demographic characteristics, mainly gender, age and education status. Educational status was divided into three categories: illiterate, literate without formal education and formal education. These categories take into account the large number of people in Ethiopia who are able to read and 
write through various educational routes, such as religious programmes and the governmental literacy programmes.

\section{Administration of assessment instruments}

Assessment instruments were administered in Amharic by lay data collectors trained for one week. The data collection was supervised in the field by trained degree-level supervisors. The instruments were piloted and pre-tested in selected sub-districts.

\section{Data management and analyses}

Data were entered into Epi-data version 3.1 and analysed using the Statistical Packages for Social Sciences, version 20 (SPSS 20; IBM Corp 2012) and Stata version 13 (Stata for Windows). Descriptive analyses (i.e., means and percentages) were used to summarise the profile of the outcomes and relevant characteristics. Logistic regression models were fitted to assess the association of the main outcomes (suicidal ideation, suicidal plan and suicide attempt) with potential risk factors. Logistic regression model was also fitted to assess potential factors associated with transition from suicidal thoughts to suicide attempt. These potential risk factors were selected a priori based on evidence from existing literature and our theoretical assumption that these factors would be relevant for the outcomes of interest.

\section{Ethical considerations}

The study was approved by the Scientific Committee of the Department of Psychiatry, Addis Ababa University, and the Institutional Review Board of the College of Health Sciences of Addis Ababa University. In all cases, informed consent was sought after adequate information about the study, and the potential benefits and risks, had been provided. Participants who were suicidal were referred for assessment by a psychiatric nurse or a psychiatrist employed or contracted by PRIME.

\section{Results}

\section{Demographic characteristics}

From the two settings, a total of 2499 participants, 1485 from the community and 1014 from health facilities, were recruited (Table 1). The non-response rate from potential participants approached in the community sample was $4.6 \%(n=71 / 1556)$ while there was no non-response in the facility sample. Over half of the participants were women $(54.3 \%)$ and married $(71.0 \%)$ and with some level of education (55.2\%). The vast majority of the participants were of the Gurage ethnic group (91.8 \%) and Orthodox Christians (89.9\%). The livelihood of most participants depended on private sector work.

\section{Prevalence non-fatal suicidal behaviour}

The 12 month prevalence of any non-fatal suicidal behaviour was $7.9 \%(N=197 / 2498)(95 \% \mathrm{CI}=6.8,8.9)$; which was significantly higher in the facility $(10.3 \%$; $95 \% \mathrm{CI}=8.4,12.1)$ than the community sample $(6.3 \%$; $95 \% \mathrm{CI}=5.0,7.5$ ) (Table 2). Nearly $6 \%$ of participants expressed plans to commit suicide: $4.6 \%$ of the community sample and $7.9 \%$ of the facility sample, which was a statistically significant difference $(P=0.001)$. The percentage who reported attempting suicide was $3.8 \%$ in the community sample and $5.4 \%$ in the facility sample, with a combined prevalence of $4.4 \%(95 \% \mathrm{CI}=3.6,5.3)$. Over half (56.4\%) of those with suicidal ideation, $60.2 \%$ in the community sample and $52.9 \%$ in the facility sample, had transitioned from ideation to attempt within the year.

\section{Help seeking}

Out of 93 community respondents that reported suicidal thought or attempt in the last 12 months, $10.8 \%(10 / 93)$ reported receiving some form of treatment (Table 2). Three of these reported receipt of treatment at a public health facility, mainly analgesics and related medical treatment, two counselling, although source of counselling was unclear, and three had traditional treatment (treatments based on local customs). None reported receiving psychothropic medications. The proportion in the facility sample who received care was slightly lower $(8.7 \%)$ but this was not statistically significant $(p=0.951)$. Overall, $60.4 \%$ did not discuss their suicidal thoughts or acts with others and this was significantly higher in the community $(77.4 \%)$ than the facility sample $(45.2 \%) \quad(p<0.001)$. Those who had discussed with others mostly did so with their family members $(n=31 / 78 ; 39.7 \%)$.

\section{Factors associated with non-fatal suicidal behaviour and suicidal transition}

Experience of depressive symptoms was the factor that was most strongly associated with non-fatal suicidal behaviour. With increasing severity of depressive symptomatology measured with the PHQ, the strength of association increased in all three categories of suicidal behaviour; suicidal ideation, plan and attempt (Table 3). Alcohol use disorder (AUDIT score of 16 and above) and Younger age (age $<25$ years) were also associated with all three forms of suicidal behaviour. The only factor associated with transition from suicidal ideation to suicidal attempt was scoring 10 and above on the PHQ $(\mathrm{O} . \mathrm{R}=2.73 ; 95$ \% CI: 1.19, 6.27).

\section{Discussion}

Non-fatal suicidal behaviour is a relatively common problem in this predominantly rural community in Ethiopia. The current findings taken together with our previous observations in this population [25] of high levels of common 
Table 1 Background characteristics of study participants

\begin{tabular}{|c|c|c|c|c|c|c|c|}
\hline \multirow[t]{2}{*}{ Characteristics } & \multicolumn{2}{|l|}{ Overall } & \multicolumn{2}{|c|}{ Community sample } & \multicolumn{2}{|c|}{ Facility sample } & \multirow[b]{2}{*}{$p$-value ${ }^{* *}$} \\
\hline & Number & Percent & Number & Percent & Number & Percent & \\
\hline \multicolumn{8}{|l|}{$\operatorname{Sex}(N=2499)$} \\
\hline Male & 1142 & 45.7 & 679 & 45.7 & 463 & 45.7 & 0.975 \\
\hline Female & 1357 & 54.3 & 806 & 54.3 & 551 & 54.3 & \\
\hline Age in years $(N=2493)$ & & & & & & & $<0.001$ \\
\hline$<25$ & 489 & 19.6 & 207 & 13.9 & 282 & 27.4 & \\
\hline $25-34$ & 710 & 28.5 & 424 & 28.6 & 286 & 28.4 & \\
\hline $35-44$ & 550 & 22.1 & 369 & 24.9 & 181 & 18.0 & \\
\hline $45-54$ & 311 & 12.5 & 205 & 13.8 & 106 & 10.5 & \\
\hline $55+$ & 433 & 17.4 & 280 & 18.9 & 153 & 15.2 & \\
\hline Marital status ( $N=2499)$ & & & & & & & $<0.001$ \\
\hline Never married & 447 & 17.9 & 178 & 12.0 & 269 & 26.5 & \\
\hline Currently married & 1773 & 71.0 & 1134 & 76.4 & 639 & 63.0 & \\
\hline Widowed/divorced & 279 & 11.2 & 173 & 11.6 & 106 & 10.5 & \\
\hline Religion ( $N=2499$ ) & & & & & & & $<0.001$ \\
\hline Orthodox & 2247 & 89.9 & 1371 & 92.3 & 876 & 86.4 & \\
\hline Muslim & 68 & 2.7 & 41 & 2.8 & 27 & 2.7 & \\
\hline Protestant & 176 & 7.1 & 71 & 4.8 & 105 & 10.4 & \\
\hline Other & 8 & 0.3 & 2 & 0.1 & 6 & 0.6 & \\
\hline Ethnicity $(N=2498)$ & & & & & & & 0.001 \\
\hline Gurage & 2292 & 91.8 & 1384 & 93.3 & 908 & 89.6 & \\
\hline Other & 206 & 8.2 & 100 & 6.7 & 106 & 10.4 & \\
\hline Educational status $(N=2495)$ & & & & & & & $<0.001$ \\
\hline illiterate & 1119 & 44.9 & 719 & 48.6 & 400 & 39.5 & \\
\hline Read and write & 449 & 18.0 & 325 & 21.9 & 124 & 12.2 & \\
\hline Formal education & 92737.2 & & 437 & 29.6 & 490 & 48.3 & \\
\hline Occupation ( $N=2489)$ & & & & & & & $<0.001$ \\
\hline Housewife & 59523.9 & & 337 & 22.8 & 258 & 25.5 & \\
\hline Private sector & 1265 & 50.8 & 888 & 60.1 & 377 & 37.3 & \\
\hline Student & 129 & 5.2 & 46 & 3.1 & 83 & 8.2 & \\
\hline Civil servant & 160 & 6.4 & 35 & 2.4 & 125 & 12.4 & \\
\hline Other & 34013.7 & & 171 & 11.6 & 169 & 16.7 & \\
\hline
\end{tabular}

*In this setting, voluntary work is something people do until they find a job. ${ }^{*} P$ values are assessing comparability of community and facility samples

mental disorders, alcohol use, and life events, are indications of the public health relevance of mental disorders.

Suicide attempt is one of the most crucial predictors of completed suicide, even four decades after the attempt had occurred, making attempted suicide an important target for the prevention of suicide [38]. Suicidal ideation is also in the pathway to completed suicide and would constitute an important target for prevention of suicide [39]. Although attending health services following suicide attempt or suicidal ideation offers an opportunity for prevention, in this study setting, most people with suicidal behaviours did not use health services.
Communication of suicidality with family members, providers or other people was also very low. The low service uptake may be explained partly by the lack of accessible services; however, the low communication of suicidality with family and providers is an important barrier for the implementation of prevention strategies. Population level interventions should target the high levels of associated stigma and condemnation in the population [40] to encourage openness on the subject. Intervention programmes being developed and delivered by PRIME in Ethiopia [26], which include packages for enhancing awareness, community inclusiveness, empowering of 
Table 2 Non-fatal suicidal behaviour and service utilisation

\begin{tabular}{|c|c|c|c|c|}
\hline \multirow[t]{2}{*}{ Characteristics } & \multicolumn{2}{|c|}{ Community sample } & \multicolumn{2}{|c|}{ Facility sample } \\
\hline & Number & Percent & Number & Percent \\
\hline \multicolumn{5}{|l|}{ Thought of taking your life } \\
\hline Yes & 93 & 6.3 & 104 & 10.3 \\
\hline No & 1391 & 93.7 & 910 & 89.7 \\
\hline \multicolumn{5}{|l|}{ Made a plan to take your own life } \\
\hline Yes & 68 & 73.1 & 80 & 76.9 \\
\hline No & 25 & 27.2 & 24 & 23.1 \\
\hline \multicolumn{5}{|l|}{ Attempted to take your own life } \\
\hline Yes & 56 & 60.2 & 55 & 52.9 \\
\hline No & 37 & 39.8 & 49 & 47.1 \\
\hline \multicolumn{5}{|c|}{ Discussed with any one about your thoughts or attempts of self harm } \\
\hline Yes & 21 & 22.6 & 57 & 54.8 \\
\hline No & 72 & 77.4 & 47 & 45.2 \\
\hline \multicolumn{5}{|l|}{ With whom did you discuss?* } \\
\hline Friend/neighbour & $4 / 21$ & 19.1 & $16 / 57$ & 28.1 \\
\hline Spouse/partner & $7 / 21$ & 33.3 & $5 / 57$ & 8.8 \\
\hline Other family member & $9 / 21$ & 42.9 & $13 / 57$ & 22.8 \\
\hline Employer/co-worker & $1 / 21$ & 4.8 & $1 / 57$ & 1.8 \\
\hline Traditional healer & $0 / 21$ & 0.0 & - - & - - \\
\hline Health care worker & $1 / 21$ & 4.8 & $0 / 57$ & 0.0 \\
\hline Religious or spiritual advisor & -— & - & $1 / 57$ & 1.8 \\
\hline Other people & - - & - & $21 / 57$ & 36.8 \\
\hline \multicolumn{5}{|c|}{ Received any treatment for thinking about or attempting to take your own life } \\
\hline Yes & 10 & 10.8 & 9 & 8.7 \\
\hline No & 83 & 88.2 & 95 & 91.3 \\
\hline PHQ total score for & & Median (IQR) & & Median (IQR) \\
\hline Non- suicidal cases & & $2(0-4)$ & & $3(1-6)$ \\
\hline Suicidal cases & & $8(5-12)$ & & $9(6-12)$ \\
\hline
\end{tabular}

${ }^{*}$ Multiple responses allowed. Because of this and rounding of decimals, percentages do not always add up to $100.0 \%$

providers and supporting health system change, have the potential to be beneficial, if tailored to suicidal behaviours.

Nevertheless, there are key gaps unaddressed in our study, which need to be considered in planning or providing interventions. This study did not explore the nature of the suicidality. For example, better information about the severity of the suicidality, the nature of the plans and what the means of the attempts were, would usefully inform public health intervention. In most rural developing country settings, organophosphate poisoning is a common method of suicide attempt and is associated with increased mortality due to lack of accessible health services [41]. Relevant triggers, such as social conflicts, family problems and financial strains should have been explored to identify targets for non-health interventions. Thus understanding the methods and immediate contexts of the attempt would inform the form and content of intervention to be provided for those with suicidal behaviour.

The factors associated with suicidality in this study, young age, alcohol use disorder and depressive symptoms, are consistent with what has been reported previously [16, 17]. However, the study was cross-sectional and thus causal interpretation of these associations can only be drawn based on previous studies.

The prevalence of non-fatal suicidal behaviour was relatively higher in this population compared to that reported in other populations in Ethiopia although rates are higher among those with symptoms of mental disorder. For example, whereas the lifetime prevalence of suicide attempt in the neighbouring district of Butajira was $3.2 \%$ [8], the prevalence among those with minor depression in the neighbouring population of the Zay and Butajira was 5 and $14 \%$ respectively $[12,13]$. During 
Table 3 Association between background demographic and clinical characteristics and non-fatal suicidal behaviours in the last 12 months

\begin{tabular}{|c|c|c|c|c|}
\hline Characteristics & $\begin{array}{l}\text { Thought of committing suicide in } \\
\text { the last } 12 \text { months }(n=2485)\end{array}$ & $\begin{array}{l}\text { Planned to commit suicide in the } \\
\text { last } 12 \text { months }(n=2485)\end{array}$ & $\begin{array}{l}\text { Attempted suicide in the } \\
\text { last } 12 \text { months }(n=2485)\end{array}$ & $\begin{array}{l}\text { Transition from thought } \\
\text { to Attempt }(n=196)\end{array}$ \\
\hline & $\begin{array}{l}\text { Adjusted Odds Ratio (aOR) } \\
(95 \% \text { Confidence Interval (CI)) }\end{array}$ & aOR $(95 \% \mathrm{Cl})$ & aOR $(95 \% \mathrm{Cl})$ & aOR $(95 \% \mathrm{Cl})$ \\
\hline \multicolumn{5}{|l|}{ Sex } \\
\hline Male & Ref & Ref & Ref & Ref \\
\hline Female & $1.48(0.97,2.25)$ & $1.58(0.98,2.56)$ & $1.32(0.76,2.27)$ & $0.96(0.46,2.06)$ \\
\hline \multicolumn{5}{|l|}{ Age in years } \\
\hline$<25$ & $2.73(1.31,5.69)$ & $2.40(1.03,5.55)$ & $3.47(1.33,9.04)$ & $1.83(0.52,6.48)$ \\
\hline $25-34$ & $1.35(0.78,2.31)$ & $1.46(0.80,2.67)$ & $1.71(0.85,3.45)$ & $1.75(0.63,4.82)$ \\
\hline $35-44$ & $1.48(0.87,2.52)$ & $1.56(0.86,2.83)$ & $1.85(0.94,3.66)$ & $1.56(0.58,4.19)$ \\
\hline $45-54$ & $1.14(0.63,2.05)$ & $1.06(0.54,2.08)$ & $1.38(0.65,2.93)$ & $1.36(0.44,4.20)$ \\
\hline $55+$ & Ref & Ref & Ref & Ref \\
\hline \multicolumn{5}{|l|}{ Marital Status } \\
\hline Never married & Ref & Ref & Ref & Ref \\
\hline Currently married & $1.55(0.84,2.85)$ & $1.66(0.82,3.36)$ & $1.64(0.74,3.61)$ & $1.06(0.37,3.00)$ \\
\hline Formerly married & $1.39(0.62,3.08)$ & $1.30(0.52,3.25)$ & $1.50(0.54,4.23)$ & $1.14(0.29,4.43)$ \\
\hline \multicolumn{5}{|l|}{ Education } \\
\hline Illiterate & Ref & Ref & Ref & Ref \\
\hline Read and write & $1.32(0.83,2.11)$ & $1.47(0.87,2.48)$ & $1.15(0.63,2.08)$ & $0.89(0.38,2.12)$ \\
\hline Formal education & $1.03(0.65,1.65)$ & $1.07(0.63,1.82)$ & $0.89(0.49,1.62)$ & $0.71(0.30,1.65)$ \\
\hline \multicolumn{5}{|l|}{ PHQ9 total score } \\
\hline$<5$ & Ref & Ref & Ref & Ref \\
\hline $5-9$ & $6.02(3.97,9.15)$ & 7.03(4.24, 11.66) & $7.33(4.05,13.39)$ & $1.73(0.75,3.96)$ \\
\hline $10+$ & $23.61(15.19,36.70)$ & $27.39(16.29,46.07)$ & $30.78(16.85,56.24)$ & $2.73(1.19,6.27)$ \\
\hline \multicolumn{5}{|l|}{ Audit total score } \\
\hline$<16$ & Ref & Ref & Ref & Ref \\
\hline $16+$ & $2.24(1.21,4.14)$ & $2.77(1.43,5.34)$ & $2.72(1.31,5.68)$ & $1.92(0.60,6.17)$ \\
\hline \multicolumn{5}{|l|}{ Sample type } \\
\hline Facility & Ref & Ref & Ref & Ref \\
\hline Community & $0.82(0.59,1.15)$ & $0.78(0.53,1.14)$ & $1.02(0.66,1.58)$ & $1.51(0.80,2.87)$ \\
\hline
\end{tabular}

a 10 year follow up of people with severe mental disorder, the rate of suicide attempt varied from $13 \%$ in schizophrenia to $26 \%$ in major depressive disorder [11].

Reason for the comparatively higher rate of suicidality in this study population may relate to the relatively higher level of mental distress, alcohol use and life events against a lower level of social support shown in our previous report [25]. This finding is also consistent with the relatively high rate of persistent suicidal preoccupations and suicide attempt assessed over a 30 day period in the same district [25]. Therefore, this higher rate of suicidality may be partly a reflection of the overall level of unmet mental health need in this population. A more detailed exploration of the context and factors contributing to suicide would have been relevant in determining the content of intervention and this is an important limitation of our study. Follow-up of this sample would also help determine shorter term clinical implications of these findings and should be considered. Although the cross-sectional nature of the study has the known limitations of recall bias and makes attribution of risk factors difficult, the study is adequate for establishing the magnitude of the problem of suicidality. Combining the community and facility sample may also introduce bias. However, the two samples were drawn from the same population (the Sodo district population) and combining would give us more power to detect relevant risk factors, especially in the analysis of suicidal attempt, which is a relatively rare but of higher public health importance. We present data separately before combining, which would 
allow interpretation of data separately. We also adjust for the source of the participant population (facility vs community) while investigating the role of other risk factors with larger sample size. Despite significant differences in the background characteristics of the two samples, study group was not a significant predictor of the target outcomes in the multivariable model. Finally, given this is a cross-sectional survey, the concept of transition from ideation to attempt may be considered inappropriate. Theoretically the two could occur at the same time although reverse causality is virtually impossible. Nevertheless, what has been attempted here is more pragmatic and the assumption has been made that, even when an attempt happens without premeditation, there is a degree of thinking that precedes any attempt.

\section{Conclusion}

The recent emphasis of the World Health Assembly is an important milestone in the context of findings such as ours suggesting a higher burden of disease related to suicidal behaviour. The WHO mental health action plan 2013-2020, identifies broad factors relevant for suicide and proposes multi-sectoral approach for the prevention of suicide. Furthermore, the action plan commits governments to reducing suicide by $10 \%$. Our data, complementing the sparse data originating from low and middle income countries, reveals that the hidden burden of suicidal behaviour is substantial. In the broader context of stigma and condemnation that may keep these behaviours hidden, public interventions to improve stigma are important. This study also indicates that addressing the need of young people, improving access to care for depression and alcohol use disorder are important next steps. Furthermore, we recommend further studies to understand the nature of the behaviour and context in which the behaviour develops, as well as developing effective brief interventions for the behaviour.

\section{Ethics approval and consent to participate}

The study was approved by the Institutional Ethics Review Board of the College of Health Sciences of Addis Ababa University (REF. 084/11/PSY). All participants took part in the study after providing informed consent.

\section{Consent for publication}

N/A.

\section{Availability of data and materials}

The data is part of an ongoing cross-country study, Programme for Improving Mental Healthcare (PRIME). Because of the ongoing and cross-country nature of the study, we are not able to make the data publicly available at present. However, data will be made available once the study is completed in the next 3 years.

\section{Abbreviations}

AUDIT: Alcohol Use Disorder Investigation Test; CIDI: Composite International Diagnostic Interview; CMD: Common Mental Disorders; LMICs: Low and Middle Income Countries; PHQ: Patient Health Questionnaire:

PRIME: Programme for Improving Mental Healthcare; SNNPR: Southern Nations, Nationalities and Peoples Region; SPSS: Statistical Packages for Social Sciences; WHO: World Health Organization; WMH: World Mental Health.

\section{Competing interests}

The authors declare that they have no competing interests.

\section{Authors' contributions}

AF, GM, CL, SDR and CH developed the study plan. MS, TS and MH supported data collection. AF, GM and $\mathrm{CH}$ participated in the data analysis. AF wrote the initial draft. All authors read the manuscripts, provided intellectual input and approved the final draft and submission.

\section{Acknowledgments}

We gratefully acknowledge the support we received from the Sodo district health office, the district administration, the health extension workers who collected the data and the supervisors.

\section{Funding}

This material has been funded by UK Aid from the UK Government, however the views expressed do not necessarily reflect the UK Government's official policies.

\section{Author details}

${ }^{1}$ Department of Psychiatry, School of Medicine, College of Health Sciences, Addis Ababa University, Addis Ababa, Ethiopia. ${ }^{2}$ Department of Psychological Medicine, Institute of Psychiatry, Psychology and Neuroscience, Centre for Affective Disorders, King's College London, London, UK. ${ }^{3}$ Aklilu Lemma Institute of Pathobiology, Addis Ababa University, Addis Ababa, Ethiopia. ${ }^{4}$ Department of Population Health, London School of Hygiene and Tropical Medicine, London, UK. ${ }^{5}$ Department of Research and Development, HealthNet Transcultural Psychosocial Organisation, Amsterdam, The Netherlands. ${ }^{6}$ Department of Psychiatry and Mental Health, Alan J Flisher Centre for Public Mental Health, University of Cape Town, Cape Town, South Africa. ${ }^{7}$ Health Service and Population Research Department, Institute of Psychiatry, King's College London, London, UK. ${ }^{8}$ Republic of Ethiopia Federal Ministry of Health, Addis Ababa, Ethiopia.

Received: 13 October 2015 Accepted: 17 March 2016

Published online: 22 March 2016

\section{References}

1. Murray CJL, Vos T, Lozano R, Naghavi M, Flaxman AD, Michaud C, Ezzati M, Shibuya K, Salomon JA, Abdalla S, et al. Disability-adjusted life years (DALYS) for 291 diseases and injuries in 21 regions, 1990-2010: a systematic analysis for the Global Burden of Disease Study. Lancet. 2010;380(9859):2197-223.

2. Borges G, Nock MK, Haro Abad JM, Hwang I, Sampson NA, Alonso J, Andrade $\mathrm{LH}$, Angermeyer MC, Beautrais $\mathrm{A}$, Bromet $\mathrm{E}$, et al. Twelve-month prevalence of and risk factors for suicide attempts in the World Health Organization World Mental Health Surveys. J Clin Psychiatry. 2010;71(12):1617-28.

3. World Health Organization. Preventing suicide: a global imperative. Geneva: WHO Press; 2014.

4. Alem A, Jacobsson L, Kebede D, Kullgren G. Awareness and attitudes of a rural Ethiopian community toward suicidal behaviour. A key informant study in Butajira, Ethiopia. Acta Psychiatr Scand Suppl. 1999:397:65-9.

5. Lester D. Suicide and islam. Arch Suicide Res. 2006;10(1):77-97.

6. Mars B, Burrows S, Hjelmeland H, Gunnell D. Suicidal behaviour across the African continent: a review of the literature. BMC Public Health. 2014;14:606.

7. Asuni T. Suicide in Western Nigeria. Br Med J. 1962;2(5312):1091-7.

8. Alem A, Kebede D, Jacobsson L, Kullgren G. Suicide attempts among adults in Butajira, Ethiopia. Acta Psychiatr Scand. 1999;100:70-6.

9. Kebede D, Alem A. Suicide attempts and ideation among adults in Addis Ababa, Ethiopia. Acta Psychiatr Scand Suppl. 1999;397:35-9.

10. Fekadu A, Hanlon C, Gebre-Eyesus E, Agedew M, Solomon H, Teferra S, Gebre-Eyesus T, Baheretibeb Y, Medhin G, Shibre T, et al. Burden of mental disorders and unmet needs among street homeless people in Addis Ababa, Ethiopia. BMC Med. 2014;12(1):138. 
11. Shibre T, Hanlon C, Medhin G, Alem A, Kebede D, Teferra S, Kullgren G, Jacobsson L, Fekadu A. Suicide and suicide attempts in people with severe mental disorders in Butajira, Ethiopia: 10 year follow-up of a population-based cohort. BMC Psychiatry. 2014;14:150.

12. Fekadu A, Alem A, Medhin G, Shibre T, Cleare A, Prince M, Kebede D. Utility of the concept of minor depressive disorder: evidence from a large rural community sample in a developing country setting. J Affect Disord. 2007;104(1-3):111-8.

13. Fekadu A, O'Donovan MC, Alem A, Kebede D, Church S, Johns L, Medhin G, Prince $M$, Shibre T. Validity of the concept of minor depression in a developing country setting. J Nerv Ment Dis. 2008;196(1):22-8.

14. Aillon JL, Ndetei DM, Khasakhala L, Ngari WN, Achola HO, Akinyi S, Ribero S. Prevalence, types and comorbidity of mental disorders in a Kenyan primary health centre. Soc Psychiatry Psychiatr Epidemiol. 2014;49(8):1257-68.

15. Agoub M, Moussaoui D, Kadri N. Assessment of suicidality in a Moroccan metropolitan area. J Affect Disord. 2006:90(2-3):223-6.

16. Gureje O, Kola L, Uwakwe R, Udofia O, Wakil A, Afolabi E. The profile and risks of suicidal behaviours in the Nigerian Survey of Mental Health and Well-Being. Psychol Med. 2007;37(6):821-30.

17. Joe S, Stein DJ, Seedat S, Herman A, Williams DR. Non-fatal suicidal behavior among South Africans : results from the South Africa Stress and Health Study. Soc Psychiatry Psychiatr Epidemiol. 2008;43(6):454-61.

18. Nock MK, Borges G, Bromet EJ, Alonso J, Angermeyer M, Beautrais A, Bruffaerts R, Chiu WT, de Girolamo G, Gluzman S, et al. Cross-national prevalence and risk factors for suicidal ideation, plans and attempts. $\mathrm{Br}$ J Psychiatry. 2008;192(2):98-105.

19. Suominen K, Isometsa E, Suokas J, Haukka J, Achte K, Lonnqvist J. Completed suicide after a suicide attempt: a 37-year follow-up study. Am J Psychiatry. 2004;161(3):562-3.

20. Nock MK, Borges G, Bromet EJ, Cha CB, Kessler RC, Lee S. Suicide and Suicidal Behavior. Epidemiol Rev. 2008;30(1):133-54.

21. Lund C, Tomlinson M, De Silva M, Fekadu A, Shidhaye R, Jordans M, Petersen I, Bhana A, Kigozi F, Prince M, et al. PRIME: a programme to reduce the treatment gap for mental disorders in five low- and middle-income countries. PLoS Med. 2012;9(12):e1001359.

22. Hanlon C, Luitel NP, Kathree T, Murhar V, Shrivasta S, Medhin G, Ssebunnya J, Fekadu A, Shidhaye R, Jordans M, et al. Challenges and opportunities for implementing integrated mental health care: a situation analysis from five low- and middle-income country districts. PLOS One 2014; In Press.

23. Byass $P$, Berhane $Y$, Emmelin A, Kebede D, Andersson T, Högberg U, Wall S. The role of demographic surveillance systems (DSS) in assessing the health of communities: An example from rural Ethiopia. Public Health. 2002;116(3):145-50.

24. Shamebo D, Muhe L, Sandström A, Wall S. The Butajira Rural Health Project in Ethiopia: Mortality Pattern of the Under Fives. J Trop Pediatr. 1991;37(5):254-61.

25. Fekadu A, Medhin G, Selamu M, Hailemariam M, Alem A, Giorgis T, Breuer E, Lund C, Prince M, Hanlon C. Population level mental distress in rural Ethiopia. BMC Psychiatry. 2014;14(1):194.

26. Fekadu A, Hanlon C, Medhin G, Alem A, Selamu M, Giorgis TW, Shibre T, Teferra S, Tegegn T, Breuer E, et al. Development of a scalable mental healthcare plan for a rural district in Ethiopia. Br J Psychiatry. 2015;207:s1-9.

27. Kessler RC, Ustun TB. The World Mental Health (WMH) Survey Initiative Version of the World Health Organization (WHO) Composite International Diagnostic Interview (CIDI). Int J Methods Psychiatr Res. 2004;13(2):93-121.

28. Kebede D, Alem A, Shibre T, Negash A, Fekadu A, Fekadu D, Deyassa N, Jacobsson L, Kullgren G. Onset and clinical course of schizophrenia in Butajira-Ethiopia-a community-based study. Soc Psychiatry Psychiatr Epidemiol. 2003;38(11):625-31.

29. Rashid E, Kebede D, Alem A. Evaluation of an Amharic version of the Composite International Diagnostic Interview (CIDI) in Ethiopia. Ethiop J Health Dev. 1996;10:69-77.

30. Babor TF, Higgins-Biddle JC, Saunders JB, Monteir MG. The Alcohol Use Disorders Identification Test: Guidelines for Use in Primary Health Care. 2nd ed. Geneva: World Health Organization; 2001.

31. World Health Organization. A user's guide to the self reporting questionnaire (SRQ). Geneva: World Health Organization; 1994.

32. Chishinga N, Kinyanda E, Weiss HA, Patel P, Ayles H, Seedat S. Validation of brief screening tools for depressive and alcohol use disorders among TB and HIV patients in primary care in Zambia. BMC Psychiatry. 2011;11:75.

33. Saunders JB, Aasland OG, Babor TF, de la Fuente JR, Grant M. Development of the Alcohol Use Disorders Identification Test (AUDIT): WHO Collaborative
Project on Early Detection of Persons with Harmful Alcohol Consumption-II. Addiction. 1993;88:791-804.

34. Fekadu A, Alem A, Hanlon C. Alcohol and drug abuse in Ethiopia: past, present and future. African Journal of drug \& alcohol studies. 2007;6:39-53.

35. Kroenke K, Spitzer RL, Williams JB. The PHQ-9: validity of a brief depression severity measure. J Gen Intern Med. 2001;16(9):606-13.

36. Gelaye B, Williams MA, Lemma S, Deyessa N, Bahretibeb Y, Shibre T, Wondimagegn D, Lemenih A, Fann JR, Stoep AV, et al. Diagnostic validity of the composite international diagnostic interview (CIDI) depression module in an East African population. Int J Psychiatry Med. 2013;46(4):387-405.

37. Hanlon C, Medhin G, Selamu M, Breuer E, Worku B, Hailemariam M, Lund C, Prince $M$, Fekadu A. Validity of brief screening questionnaires to detect depression in primary care in Ethiopia. J Affect Disord. 2015;186:32-9.

38. Dahlgren KG. Attempted suicide—-35 years afterward. Suicide Life Threat Behav. 1977:7:75-9.

39. Vandivort DS, Locke BZ. Suicide Ideation: Its Relation to Depression, Suicide and Suicide Attempt. Suicide and Life-Threatening Behavior. 1979:9(4):205-18.

40. Alem A, Jacobsson L, Kebede D, Kullgren G. Awareness and attitudes of a rural Ethiopian community toward suicidal behaviour: A key informant study in Butajira, Ethiopia. Acta Psychiatr Scand. 1999;100:65-9.

41. Eddleston M. Patterns and problems of deliberate self-poisoning in the developing world. Q J Med. 2000:93:715-31.

\section{Submit your next manuscript to BioMed Central and we will help you at every step:}

- We accept pre-submission inquiries

- Our selector tool helps you to find the most relevant journal

- We provide round the clock customer support

- Convenient online submission

- Thorough peer review

- Inclusion in PubMed and all major indexing services

- Maximum visibility for your research

Submit your manuscript at www.biomedcentral.com/submit

) Biomed Central 